\title{
Sarcopenia is a Significant Predictor of Mortality After Abdominal Aortic Aneurysm Repair
}

\author{
Joshua K. Kays, MD*, Tiffany W. Liang, MD*, Teresa A. Zimmers, PhD, Daniel P. Milgrom, \\ MD, Hamzah Abduljabar, BS, Andrew Young, BS, Bradford J. Kim, MD MHS, Teresa M. Bell, \\ PhD, Andres Fajardo, MD, Michael P. Murphy, MD, and Leonidas G. Koniaris, MD MBA \\ Department of Surgery, Indiana University School of Medicine, Indianapolis, IN 46202
}

\begin{abstract}
Aims-Repair of abdominal aortic aneurysms (AAA) decreases the incidence of rupture and death. In cancer patients, sarcopenia has been associated with increased surgical complications and mortality. The impact of sarcopenia on survival after AAA repair has yet to be described.

Methods and Results-Patient demographic, laboratory, body composition measurements and survival data were obtained from patients undergoing AAA repair at the Indiana University medical campus over a 5-year period. Univariate and multivariate analyses were performed to identify factors associated with overall survival. Overall, $58.2 \%$ presented with sarcopenia. Sarcopenic patients were older $(71.8 \pm 8.3$ versus $66.8 \pm 8.1$ years; $\mathrm{p}<0.001)$, had lower body mass index (BMI) $\left(26.3 \pm 5.2\right.$ versus $\left.31.5 \pm 5.9 \mathrm{~kg} / \mathrm{m}^{2} ; \mathrm{p}<0.001\right)$, higher rates of myosteatosis $(84.4 \%$ versus 52.\%; $\mathrm{p}<0.001)$, greater AAA diameter $(60.6 \pm 14.0$ versus $57.8 \pm 11.7 \mathrm{~mm} ; \mathrm{p}=0.016)$, higher Charlson Comorbidity Index (CCI) (32.3\% versus $25.1 \% \quad 26$; $\mathrm{p}=0.034)$, and increased rates of rupture ( $8.2 \%$ versus $3.8 \% ; \mathrm{p}=0.047)$. Sarcopenic and nonsarcopenic patients had no difference in 30 -day morbidity ( $8.5 \%$ versus $8.5 \%$; $\mathrm{p}=0.991$ ) or mortality $(3.7 \%$ versus $0.9 \% ; \mathrm{p}=0.07)$. Univariate analysis demonstrated age, sarcopenia, myosteatosis, CCI, and BMI to be associated with long-term survival. There was no correlation between BMI and sarcopenia. Both sarcopenia and myosteatosis resulted in decreased one-, three-, and five-year survivals compared to their counterparts. On multivariate analysis sarcopenia is independently associated with survival,
\end{abstract}

\footnotetext{
This is an open-access article distributed under the terms of the Creative Commons Attribution License, which permits unrestricted use, distribution, and reproduction in any medium, provided the original author and source are credited.

Address for correspondence: Leonidas G. Koniaris MD MBA, Department of Surgery, EH 511 SGEN, Indianapolis, IN 46202, Tel: (317) 217-2812, 1koniari@iu.edu.

-co-first authors

Conflicts of Interest Statement

Joshua K. Kays, Tiffany W. Liang, Teresa A. Zimmers, Daniel P. Milgrom, Hamzah Abduljabar, Andrew Young, Bradford J. Kim, Teresa M. Bell, Andres Fajardo, Michael P. Murphy and Leonidas G. Koniaris certifiy that they have NO affiliations with or involvement in any organization or entity with any financial interest (such as honoraria; educational grants; participation in speakers' bureaus; membership, employment, consultancies, stock ownership, or other equity interest; and expert testimony or patent-licensing arrangements), or non-financial interest (such as personal or professional relationships, affiliations, knowledge or beliefs) in the subject matter or materials discussed in this manuscript.

The authors certify that they comply with the ethical guidelines for authorship and publishing of the Journal of Cachexia, Sarcopenia and Muscle-Clinical Reports (von Haehling S, Ebner N, Morley JE, Coats AJS, Anker SD. Ethical guidelines for authorship and publishing in the Journal of Cachexia, Sarcopenia and Muscle?Clinical Reports. J Cachexia Sarcopenia Muscle Clinical Reports 2016; $1 ; \mathrm{e} 28: 1-2$.
} 
conferring a 1.6-fold increase in death $(\mathrm{p}=0.04)$. The combination of sarcopenia plus myosteatosis doubled the risk of death compared to sarcopenia alone.

Conclusions-This is the first study to demonstrate that over half of all patients undergoing AAA repair are sarcopenic, a condition associated with increased mortality. Sarcopenia with myosteatosis is associated with double the mortality of sarcopenia alone. CT scan, but not BMI, accurately identifies sarcopenia and myosteatosis. Defining the mechanisms through which sarcopenia contributes to late death after AAA repair is critical to developing novel interventions that may improve survival in this high risk population.

\section{Keywords}

Abdominal aortic aneurysm; Sarcopenia; Myosteatosis; Prognosis; Survival

\section{Introduction}

The primary focus in improving survival in patients with abdominal aortic aneurysms (AAA) has been centered on the timing of surgical repair to prevent the catastrophic consequences of aneurysm rupture. Intensive population based studies have provided detailed guidelines for intervention that rely on factors associated with risk of rupture that include maximal transverse diameter, growth rate, aneurysm morphology, and symptoms (1). While these efforts have had a significant impact in decreasing complications from rupture, assessing mid- and long-term outcomes post AAA repair has largely been ignored (2-5).

In recent years, body composition has emerged as a novel prognostic indicator in both malignant and non-malignant diseases (6-8). Sarcopenia, or low muscle mass for height, is a catabolic state associated with an inflammatory condition(9). Futhermore, sarcopenia has been associated with increased morbidity and mortality risk following major surgical procedures (10). Inflammation has been implicated as a driving mechanism for the development of sarcopenia(11). Tumor necrosis factor-alpha (TNF-a), interleukin-1beta (IL-1 $\beta$ ), and interleukin-6 (IL-6) promote muscle wasting by increasing protein degradation and decreasing protein synthesis (12-14). Inflammation has been shown to be associated with AAA as well. Microscopic examination of AAA have shown inflammatory cells infiltrating the aneurysms $(15,16)$. In addition, patients with AAA have elevated levels of inflammatory cytokines, which in turn, activate matrix metalloproteinases (MMPs) (17-20). The activation of MMP favors collagen and elastin degradation leading to aortic wall weakening and aneurysm formation(20).

Cross-sectional skeletal muscle and adipose tissue masses at the level of the third lumbar (L3) vertebrae have been shown to correlate with overall body measurements of each tissue types (21). Using specifically designed software body composition measurements can be readily obtained from computed tomography (CT) scans that are a standard part of the preoperative evaluation for patients undergoing endovascular or open AAA repair. Thus, body composition may be a predictor of post-AAA morbidity and mortality.

Herein, we evaluated the impact of body composition on short- and long-term outcomes after AAA repair. We hypothesize that patients with sarcopenia, determined by CT derived 
L3 skeletal muscle measurements at the time of AAA repair, will have increased surgical complications and decreased post-operative survival when controlling for other factors. Based upon data examining 505 patients undergoing elective and urgent AAA repair at Indiana University (IU) we demonstrate that the presence of sarcopenia is a significant predictor of survival at five years post-AAA repair.

\section{Methods}

This study was approved by the Indiana University Institutional Review Board and carried out in compliance with the IU Standard Operating Procedures for Research Involving Human Subjects and therefore have been performed in accordance to the ethical standards laid down in the 1964 Declaration of Helsinki and its later ammendments.

Selection of patients is outlined in Figure 1. All patients presenting to Indiana University Methodist Hospital between January 1, 2012 and July 30, 2015 and the Richard L. Roudebush Veterns Administration Medical Center (RRVAMC) between July 1, 2005 and July 30, 2015 for repair of AAA were eligible for inclusion. Patients from RRVAMC were obtained through a query of the electronic medical record (EMR). The Vascular Quality Initiative database was used to obtain patients from IU Methodist Hospital. Together these searches identified seven hundred forty-two total patients. One hundred eight did not meet inclusion criteria. One hundred twenty-nine patients were excluded for the following reasons: sixty-six had no available $\mathrm{CT}$ scan, thirty-nine had CT scan of inadequate quality for analysis, sixteen had corrupted CT files that could not be analyzed, and eight had incomplete clinical data.

Body composition analysis was performed on five-hundred five patients using Slice-OMatic ${ }^{\circledR}$ software Version 4.3 (Tomovision, Montreal, Quebec, Canada) by the following method: cross-sectional area $\left(\mathrm{cm}^{2}\right)$ was measured and recorded for skeletal muscle (SKM), visceral adipose tissue (VAT), subcutaneous adipose tissue (SCAT), and mean skeletal muscle density (SKM HU) at the level of the third lumbar vertebrae (L3)(21). Hounsfield thresholds were set at -29 to +50 for SKM, -50 to -150 for VAT, and -30 to -190 for SCAT. Two consecutive images were analyzed and the mean of the two images were normalized to height in meters squared to establish tissue specific indices $\left(\mathrm{cm}^{2} / \mathrm{m}^{2}\right)$. Total muscle measurements included rectus abdominus, external and internal oblique, transversus abdominus, psoas, erector spinae, and quadratus lumborum.

Sarcopenia was defined as skeletal muscle index (SKMI) $<52.4 \mathrm{~cm}^{2} / \mathrm{m}^{2}$ for males and $<38.5$ $\mathrm{cm}^{2} / \mathrm{m} 2$ for females (22). Myosteatosis was defined as mean skeletal muscle density $<33 \mathrm{HU}$ for patients with body mass index (BMI) $22 \mathrm{~kg} / \mathrm{m}^{2}$ and $<41 \mathrm{HU}$ for patients with BMI $<25$ $\mathrm{kg} / \mathrm{m}^{2}$ (6). BMI classification was based on the World Health Organization (WHO) definitions (23). Patients meeting the criteria for sarcopenia and obesity were classified as having sarcopenic obesity. Complications were defined as any deviation from normal recovery including the need for a procedural intervention within 30 days of the index operation. 


\section{Statistical Analysis}

The primary outcome measured was overall survival calculated from the time of surgery to the time of death or last follow up. The main prognostic factor was presence of pre-operative sarcopenia, however secondary prognostic factors included age, sex, AAA diameter, preoperative myosteatosis, BMI classification, and CCI. Age and AAA diameter were treated as continuous variables for Cox proportional models. CCI was divided into the following three categories: $3,4-5$, and $\ 6$ for Kaplan-Meier and Cox proportional models. Sarcopenia, myosteatosis, and sex were treated as categorical variables for Kaplan-Meier and Cox proportional models. Kaplan-Meier analyses are reported as median survival in months with $\log$-based $\mathrm{p}$ values. Cox proportional models are reported as hazard ratios with $95 \%$ confidence intervals with $\mathrm{p}$ values.

Mean age, BMI, SKMI, SKM HU, AAA, and estimated blood loss (EBL) were compared between sarcopenic and non-sarcopenic groups by independent t-test. Sex, repair method, myosteatosis, complications (overall), race, and rupture were compared between groups using Pearson's chi-squared test. CCI and American Society of Anesthesiologist (ASA) score were compared between groups using Mann-Whitney U test. SKMI measurements between BMI categories were compared by sex by ANOVA. All $\mathrm{p}$ values are two-sided.

Multivariate analysis was performed using Cox proportional models. All variables found to be significantly associated with survival on univariate analysis were included in the model. Two models were created; one which included BMI and excluded sarcopenia and myosteatosis while the second model included sarcopenia and myosteatosis and excluded BMI. Two models were required due to the BMI's dependence on body composition. Sarcopenia and myosteatosis are classifications of body composition. BMI is therefore influenced by sarcopenia and myosteatosis status. All variables in a multivariate model must be independent or the model will not be accurate, thus the need for two models. Age and $\mathrm{CCI}$ were treated as a continuous variable for both models. BMI was treated as a categorical variable and was categorized by WHO classification.

All statistical analyses were performed using IBM SPSS Statistics for Windows version 23.0 (Chicago, IL). Images for Kaplan-Meier curves and graphs were created using GraphPad Prism version 7 (GraphPad software, La Jolla, CA). Significance was set at $\mathrm{p}<0.05$ for all results.

\section{Results}

Baseline patient characteristics are summarized in Table 1. Using values of sarcopenia determined for cancer patients (22), we observed that $58.2 \%$ of patients had sarcopenia compared to $41.2 \%$ without. Sarcopenic patients were older ( $71.8 \pm 8.3$ vs. $66.8 \pm 8.1$ years; $\mathrm{p}<0.001)$, had larger AAA diameter $(60.6 \pm 14.0$ vs. $57.8 \pm 11.7 \mathrm{~mm} ; \mathrm{p}=0.01)$, increased comorbidities ( $32.3 \%$ vs. $25.1 \% \mathrm{CCI} \nsucceq 6 ; \mathrm{p}=0.03)$, and increased rates of rupture ( $8.2 \%$ vs. $3.8 \% ; \mathrm{p}=0.05$ ) than non-sarcopenic patients. With regards to body composition analyses sarcopenic patients had lower BMI (26.3 \pm 5.2 vs. $\left.31.5 \pm 5.9 \mathrm{~kg} / \mathrm{m}^{2} ; \mathrm{p}<0.001\right)$, lower SKMI ( $43.7 \pm 6.7$ vs. $58.7 \pm 8.3 \mathrm{~cm} 2 / \mathrm{m} 2 ; \mathrm{p}<0.001)$, less dense skeletal muscle ( $28.5 \pm 11.1$ vs. $33.0 \pm 7.1 \mathrm{HU} ; \mathrm{p}<0.001)$, and higher rates of myosteatosis ( $84.4 \%$ vs. $52.1 \% ; \mathrm{p}<0.001)$. 
There was no difference in 30-day post-operative morbidity rate ( $8.5 \%$ vs. $8.5 \% ; \mathrm{p}=0.99)$ or 30 -day post-operative mortality rate $(0.9 \%$ vs. $3.7 \%$; $=0.07)$ between patients with sarcopenia and those without sarcopenia.

Univariate Kaplan-Meier survival analysis showed that sarcopenic patients had significantly decreased overall survival from non-sarcopenic patients (Figure 2A), along with decreased one, three, and five-year survivals (Figure 2B). Patients with myosteatosis also had significantly decreased overall survival than patients without myosteatosis (Figure 2C) and decreased one, three, and five-year survivals (Figure 2D).

Univariate Cox proportional modeling showed increasing age, sarcopenia, myosteatosis, increasing CCI, and BMI to each be associated with increased risk of mortality (Table 2). Multivariate model 1 showed sarcopenia and increasing CCI to be independently associated with increased risk of mortality (Table 2, Model 1). Sarcopenia had the greatest influence on mortality in this model carrying a 1.6 fold increased risk of death (Table 2, Model 1). Furthermore, sarcopenia was identified in eighty-four of the one-hundred fifteen patient deaths, representing $73 \%$ of deaths (Figure 3A), while myosteatosis was identified in ninetyfour, or $82 \%$, of all patient deaths (Figure 3B). Patients with sarcopenia plus myosteatosis had shorter overall survival than patients with sarcopenia alone or myosteatosis alone (Figure 3C). In fact, the combination of sarcopenia plus myosteatosis doubled mortality (Figure 3D). Multivariate model 2 (Table 2, Model 2) showed increasing age, increasing $\mathrm{CCI}$, and BMI classification of underweight to be significantly associated with increased mortality, while BMI classification of overweight was associated with decreased mortality.

Kaplan-Meier survival analysis comparing obese patients with sarcopenia (sarcopenic obesity) to obese patients without sarcopenia shows significant difference in survival (Figure 4A). Cox proportional modeling show sarcopenic obesity confers a 3.5 fold increased risk of mortality compared to patients with nonsarcopenic obese patients (HR=3.5; 95\% CI=1.67.9).

Mean BMI for patients with sarcopenia is significantly lower than those without sarcopenia (26.3 vs. $31.5 \mathrm{~kg} / \mathrm{m}^{2}$ )(Figure 4B). SKMI measurements were compared among BMI categories for both males (Figure 4C) and females (Figure 4D). All BMI categories had significantly different SKMI measurements for both sexes. Furthermore, 87.1\%, 64.9\%, and $34 \%$ of males in the normal, overweight, and obese BMI categories had SKMI measurements that qualified as sarcopenic, while $85.7 \%$ and $37.5 \%$ of females in the normal and overweight BMI categories had SKMI measurements which qualified as sarcopenic. Overall, $85.7 \%$ of underweight, $86.9 \%$ of normal, $62.6 \%$ of overweight, and $33.3 \%$ of obese BMI patients had SKMI measurements that fell into the sarcopenic category.

\section{Discussion}

According to the Society of Vascular Surgeons (SVS), approximately 200,000 individuals will be diagnosed with abdominal aortic aneurysms each year, and 40,000 endovascular and open repairs are performed annually to prevent rupture (24). This study identifies sarcopenia, a condition of abnormally low skeletal muscle mass, to be an independent 
predictor of mortality after AAA repair. Sarcopenic patients were found to have decreased one, three, and five-year survival compared to non-sarcopenic patients, and was present in $73 \%$ of all deaths. More alarming was the fact that the combination of sarcopenia with myosteatosis doubled the mortality over sarcopenia alone.

The current study is the largest, most comprehensive study specifically examining body composition and outcomes after AAA repair. There is a growing body of literature on the negative effect of sarcopenia on surgical outcomes and mortality. Both Lee et al. and Drudi et al. demonstrated increased risk of mortality after AAA repair with decreasing total psoas muscle $(25,26)$. However, both studies defined sarcopenia based on the lowest tertile within the study group, making their definition susceptible to selection bias. Our study uses an established, validated, sex-specific definition of sarcopenia which did not rely on the current patient population being studied, thus eliminating any selection bias (22). The results, however, are consistent with Lee et al. and Drudi et al. We establish sarcopenia is a major prognostic indicator for patients who have undergone AAA repair, but does not appear to influence 30-day outcomes. The data provides sex-specific values that clinicians can use clinically to identify patients with sarcopenia that are at high risk of death following successful repair. This study also identifies the combination of sarcopenia plus myosteatosis as a significant risk factor, doubling the risk of mortality after AAA repair compared to sarcopenia alone.

The presence of sarcopenia is a risk factor independent of other known risk factors in AAA patients. Age, congestive heart failure, cerebral vascular disease, and diabetes mellitus have all been shown to increase the risk of mortality after AAA repair (27). This study, which included congestive heart failure, cerebral vascular disease and diabetes mellitus by proxy by utilizing the CCI, found that sarcopenia had significant, independent association with mortality by multivariate analysis.

Based on these results, any evaluation of a patient for AAA repair should monitor for sarcopenia and myosteatosis, as well as the other clinical factors that have been associated with poor outcomes. Targeting these patients, ideally before, and surely after AAA repair, may prove to be beneficial, thus the mechanisms mediating death in these patients need to be elucidated to aid in developing methods to reduce the risk.

A second significant finding is related to obesity and sarcopenia. Obesity has been reported to increase the risk of mortality after AAA repair; however, the data herein contradict these previous findings (28). A break down of SKMI measurements by BMI category showed that BMI is not an accurate reflection of lean body mass, specifically the absence or presence of sarcopenia. The majority of patients with normal BMIs (87\%) and overweight BMIs (63\%) met the criteria for sarcopenia. Even patients with BMI's that categorize them as obese had $33 \%$ rate of meeting the criteria for sarcopenia. Further comparison showed obese patients with sarcopenia had significantly decreased survival than obese patients without sarcopenia. This suggests that lower rates of sarcopenia are the reason that obesity had a protective effect in this study and further demonstrates the adverse effects of sarcopenia. These data suggest abandoning BMI as a useful measure for AAA patients in lieu of sarcopenia measurements. 
Only twenty-two percent of patients did not have sarcopenia, myosteatosis, or a combination of the two. The high rate of muscle abnormalities among all patients in this study suggests disruption of normal muscle metabolism in patients with AAA that is associated with death and is strikingly similar to the patterns of cachexia seen in cancer patients. While it has been shown in certain populations that muscle mass and function can be improved with exercise and supplemental protein, the muscle wasting in cancer cachexia, by definition, is resistant to reversal by conventional nutritional support (29-31). Several cytokines have been linked to the muscle wasting seen in cancer cachexia including tumor necrosis factor-alpha (TNFa), interleukin (IL)-1, IL-6, and interferon-gamma (IFN- $\gamma$ ) (32-38). TNF-a, IL-1 $\beta$, IL-6, and IFN- $\gamma$ are produced by AAA $(39,40)$. Patients with AAA have also been shown to have elevated circulatory serum levels of TNF- $\alpha$, IL-1 $\beta$, IL- 6 and these cytokines have been implicated in the pathogenesis of AAA $(17,39)$. During repair the aneurysmal tissue is not excised, and like cancer, may act as a non-healing wound, continuing to drive inflammation and production of cachexia-associated cytokines. This study highlights the importance of identifying the mechanism and correcting the muscle metabolism disruption in AAA patients. This hopefully may result in significantly increased long-term survival after repair.

While this is the largest, most comprehensive study of its kind, there are still some limitations. This is a single-institution, retrospective study, and although the results should be generalizable due to the magnitude of the cohort, the cohort was largely male Caucasians; application of the results to females and minorities populations should be done with caution. There was also an age difference between the sarcopenic and non-sarcopenic groups. The authors do not believe this to be a limitation, however, because when controlling for age in the multivariate analysis sarcopenia remained a significant negative prognostic factor.

For various reasons, thirty-two percent (237/742) of patients who presented to the institution for AAA repair were not able to be included in the study. It would be unlikely that inclusion of these patients would have a significant effect on the results, as the patient cohort of fivehundred five patients still represents a very large patient population. The authors believe that inclusion of these patients would only strengthen the results observed.

Despite these limitations, this study demonstrates sarcopenia as a common comorbidity in AAA patients undergoing repair that is independently associated with long-term all-cause mortality. It is imperative for sarcopenia to be integrated into all patient evaluations prior to open or endovascular AAA repair. The presence of sarcopenia should not exclude a patient from undergoing repair of an AAA, but rather be used to identify a subset of patients who are vulnerable to poor outcomes. Sarcopenic patients may benefit from pre- and postoperative interventions targeted at improving muscle mass and quality.

\section{Sources of Funding}

This work was funded in part by grants to LGK from the NIH (R01DK096167) and the Lilly Endowment, Inc.

\section{References}

1. Kent KG. Abdominal aortic aneurysms. N Engl J Med 2014;371:2101-8. [PubMed: 25427112] 
2. Szilagyi DE, Smith RF, DeRusso FJ, Elliot JP, Sherrin FW. Contribution of abdominal aortic aneurysmectomy to prolong life. Ann Surg 1996;164:678-99.

3. Powell JT, Greenhalgh RM. Small abdominal aortic aneurysms. N Engl J Med 2003;348:1895-901. [PubMed: 12736283]

4. Lederle FA, Johnson GR, Wilson SE, Ballard DJ, J WD Jr., Blebea J, Littooy FN, Freischlag JA, Bandyk D, Rapp JH, Salam AA. Rupture rate of large abdominal aortic aneurysms in patients refusing or unfit for elective repair. JAMA 2002;287:2968-72. [PubMed: 12052126]

5. Lederle FA, Wilson SE, Johnson GR, Reinke DB, Littooy FN, Acher CW, Ballard DJ, Messina LM, Gordon IL, Chute EP, Krupski WC, Busuttil SJ, Barone GW, Sparks S, Graham LM, Rapp JH, Makaroun MS, Moneta GL, Cambria RA, Makhoul RG, Eton D, Ansel HJ, Freischlag JA, Bandyk D. Immediate repair compared to surveillance of small abdominal aortic aneurysms. N Engl J Med 2002;346:1437-44. [PubMed: 12000813]

6. Martin L, Birdsell L, MacDonald N, Reiman T, Clandinin MT, McCargar LJ, Murphy R, Ghosh S, Sawyer MB, Baracos VE. Cancer cachexia in the age of obesity: skeletal muscle depletion is a powerful prognostic indicator, independent of body mass index. J Clin Oncol 2013;31:1539-47. [PubMed: 23530101]

7. Tan BHL, Birdsell LA, Martin L, Baracos VE, Fearon KCH. Sarcopenia in an overweight and obese patient is an adverse prognostic factor in pancreatic cancer. Clin Cancer Res 2009;15:6973-9. [PubMed: 19887488]

8. Jones SE, Maddocks M, Kon SSC, Canavan JL, Nolan CM, Clark AL, Polkey MI, Man WD-C. Sarcopenia in COPD: prevalence, clinical correlates and response to pulmonary rehabilitation. Thorax 2015;70:213-8. [PubMed: 25561517]

9. Cruz-Jentoft AJ, Baeyens JP, Bauer JM, Boirie Y, Cederholm T, Landi F, Martin FC, Michel J-P, Rolland Y, Schneider SM, Topinková E, Vandewoude M, Zamboni M. Sarcopenia: European consensus on definition and diagnosis: Report of the European Working Group on sarcopenia in older people. Age and ageing 2010;39:412-23. [PubMed: 20392703]

10. Friedman J, Lussiez A, Sullivan J, Wang S, Englesbe M. Implications of sarcopenia in major surgery. Nutr Clin Pract 2015;30:175-9. [PubMed: 25681482]

11. Walrand S, Guillet C, Salles J, Cano N, Boirie Y. Physiopathological Mechanism of Sarcopenia. Clin Geriatr Med 2011;27:365-85. [PubMed: 21824553]

12. Fong Y, Moldawer LL, Marano M, Wei H, Barber A, Manogue K, Tracey KJ, Kuo G, Fischman DA, Cerami A. Cachectin/TNF or IL-1 induces cachexia with redistribution of body proteins. Am J Physiol Regul Integr Physiol 1989;256:R659-R65.

13. Ch Lang, Frost RA Nairn AC, MacLean DA Vary TC. TNF-alpha impairs heart and skeletal muscle protein synthesis by altering translation initiation. Am J Physiol Endocrinol Metab 2002;282:E336-E47. [PubMed: 11788365]

14. Zoico E, Roubenoff R. The role of cytokines in regulating protein metabolism and muscle function. Nutr Rev 2002;60:39-51. [PubMed: 11852969]

15. Koch AE, Haines GK, Rizzo RJ, Radosevich JA, Pope RM, Robinson PG, Pearce WH. Human abdominal aortic aneurysms. Immunophenotypic analysis suggesting an immune-mediated response. Am J Pathol 1990;137:1199-213. [PubMed: 1700620]

16. Brophy CM, Reilly JM, Smith GJW, Tilson MD. The role of inflammation in nonspecific abdominal aortic aneurysm disease. Ann Vasc Surg 1991;5:229-33. [PubMed: 2064915]

17. Juvonen J, Surcel H-M, Satta J, Teppo A-M, Bloigu A, Syrjälä H, Airaksinen J, Leinonen M, Saikku P, Juvonen T. Elevated circulating level of inflammatory cytokines in patients with abdominal aortic aneurysm. Arterioscler Thromb Vasc Biol 1997;17:2843-7. [PubMed: 9409264]

18. Rohd LEP, Arroyo LH, Rifai N, Creager MA, Libby P, Ridker PM, Lee RT. Plasma concentrations of IL-6 and abdominal aorta diameter among subjects without aortic dilation. Arterioscler Thromb Vasc Biol 1999;19:1695-9. [PubMed: 10397687]

19. Jones KG, Brull DJ, Brown LC, Sian M, Greenhalgh RM, Humphries SE, Powell JT. Interleukin-6 (IL-6) and the prognosis of abdominal aortic aneurysms. Circulation. 2001;103:2260-5. [PubMed: 11342474]

20. Ailawadi G, Eliason JL, Jr GRU. Current concepts in pathogenesis of abdominal aortic aneurysm. J Vasc Surg 2003;38:584-8. [PubMed: 12947280] 
21. Shen W, Punyanitya M, Wang Z, Gallagher D, St.-Onge M-P, Albu J, Heymsfield SB, Heshka S. Total body skeletal muscle and adipose tissue volumes: estimation from a single abdominal crosssectional image. J Appl Physiol 2004;97:2333-8. [PubMed: 15310748]

22. Prado CMM, Lieffers JR, McCargar LJ, Reiman T, Sawyer MB, Martin L, Baracos VE. Prevalence and clinical implications of sarcopenic obesity in patients with solid tumours of the respiratory and gastrointestinal tracts: a population-based study. Lancet Oncol 2008;9:629-35. [PubMed: 18539529]

23. Organization WH. What is overweight and obesity 2017 [cited 2017 May 16, 2017]. Available from: http://www.who.int/dietphysicalactivity/childhood_what/en/.

24. Singh MJ. Abdominal aortic aneurysm: Society for Vascular Surgery; 2017 [cited 2017 May 16, 2017]. Available from: https://vascular.org/patient-resources/vascular-conditions/abdominal-aorticaneurysm.

25. Lee JS-J, He K, Harbaugh CM, Schaubel DE, Sonnenday CJ, Wang SC, Englesbe MJ, Eliason JL. Frailty, core muscle size, and mortality in patients undergoing open abdominal aortic aneurysm repair J Vasc Surg 2011;53:912-7. [PubMed: 21215580]

26. Drudi LM, Phung K, Ades M, Zuckerman J, Mullie L, Steinmetz OK, Obrand DI, Afilalo J. Psoas muscle area predicts all-cause mortality after endovascular and open aortic aneurysm repair. Eur J Vasc Endovasc Surg 2016;52:764-9. [PubMed: 27776940]

27. Schlosser F, Vaatjes I, Heijden GJMGvd, Moll FL, Verhagen HJM, Muhs BE, deBorst GJ, Groenestege ATT, Kardaun JWPF, deBruin A, Reitsma J, Graaf Yvd, Bots M. Mortality after elective abdominal aortic aneurysm repair. Ann Surg 2010;251:158-64. [PubMed: 19838103]

28. Giles KA, Wyers MC, Pomposelli FB, Hamdan AD, Ching YA, Schermerhorn ML. The impact of body mass index on perioperative outcomes of open and endovascular abdominal aortic aneurysm repair from the National Surgical Quality Improvement Program, 2005-2007. J Vasc Surg 2010;52:1471-7. [PubMed: 20843627]

29. Kim HK, Suzuki T, Saito K, Yoshida H, Kobayashi H, Kato H, Katayama M. Effects of exercise and amino acid supplementation on body composition and physical function in communitydwelling elderly Japanese sarcopenic women: a randomized controlled trial. J Am Geriatr Soc 2012;60:16-23. [PubMed: 22142410]

30. Zdzieblik D, Oesser S, Baumstark MW, Gollhofer A, König D. Collagen peptide supplementation in combination with resistance training improves body composition and increases muscle strength in elderly sarcopenic men: a randomised controlled trial. Br J Nutr 2015;114:1237-45. [PubMed: 26353786]

31. Fearon K, Strasser F, Anker SD, Bosaeus I, Bruera E, Fainsinger RL, Jatoi A, Loprinzi C, MacDonald N, Mantovani G, Davis M, Muscaritoli M, Ottery F, Radbruch L, Ravasco P, Walsh D, Wilcock A, Kaasa S, Baracos VE. Definition and classification of cancer cachexia: an international consensus. Lancet Oncol 2011;12:489-95. [PubMed: 21296615]

32. Zimmers TA, Davies MV, Koniaris LG, Haynes P, Esquela AF, Tomkinson KN, McPherron AC, Wolfman NM, Lee S-J. Induction of cachexia in mice by systemically administered myostatin. Science. 2002;296:1486-8. [PubMed: 12029139]

33. Klimek MEB, Aydogdu T, Link MJ, Pons M, Koniaris LG, Zimmers TA. Acute inhibition of myostatin-family proteins preserves skeletal muscle in mouse models of cancer cachexia. Biochem Biophys Res Comm 391:1548-54.

34. Aoyagi T, Terracina KP, Raza A, Matsubara H, Takabe K. Cancer cachexia, mechanism and treatment. World J Gastrointest Oncol 2015;7:17-29. [PubMed: 25897346]

35. Argiles JM, Busquets S, Toledo M, Lopez-Soriano FJ. The role of cytokines in cancer cachexia. Curr Opin Support Palliat Care 2009;3:263-8. [PubMed: 19713854]

36. Zimmers TA, Fishel ML, Bonetto A. STAT3 in the systemic inflammation of cancer cachexia. Sem Cell Dev Biol 2016;54:28-41.

37. Bonetto A, Aydogdu T, Jin X, Zhang Z, Zhan R, Puzis L, Koniaris LG, Zimmers TA. JAK/STAT3 pathway inhibition blocks skeletal muscle wasting downstream of IL-6 and in experimental cancer cachexia. Am J Physiol Endocrinol Metab 2012;303:E410-E21. [PubMed: 22669242] 
38. Bonetto A, Aydogdu T, Kunzevitzky N, Guttridge DC, Khuri S, Koniaris LG, Zimmers TA. STAT3 activation in skeletal muscle links muscle wasting and the acute phase response in cancer cachexia. PLOSOne. 2011;6:e22538.

39. Chang TW, Gracon ASA, Murphy MP, Wilkes DS. Exploring autoimmunity in the pathogensis of abdominal aortic aneurysms. Am J Physiol Heart Circ Physiol 2015;309:H719-H27. [PubMed: 26116712] 


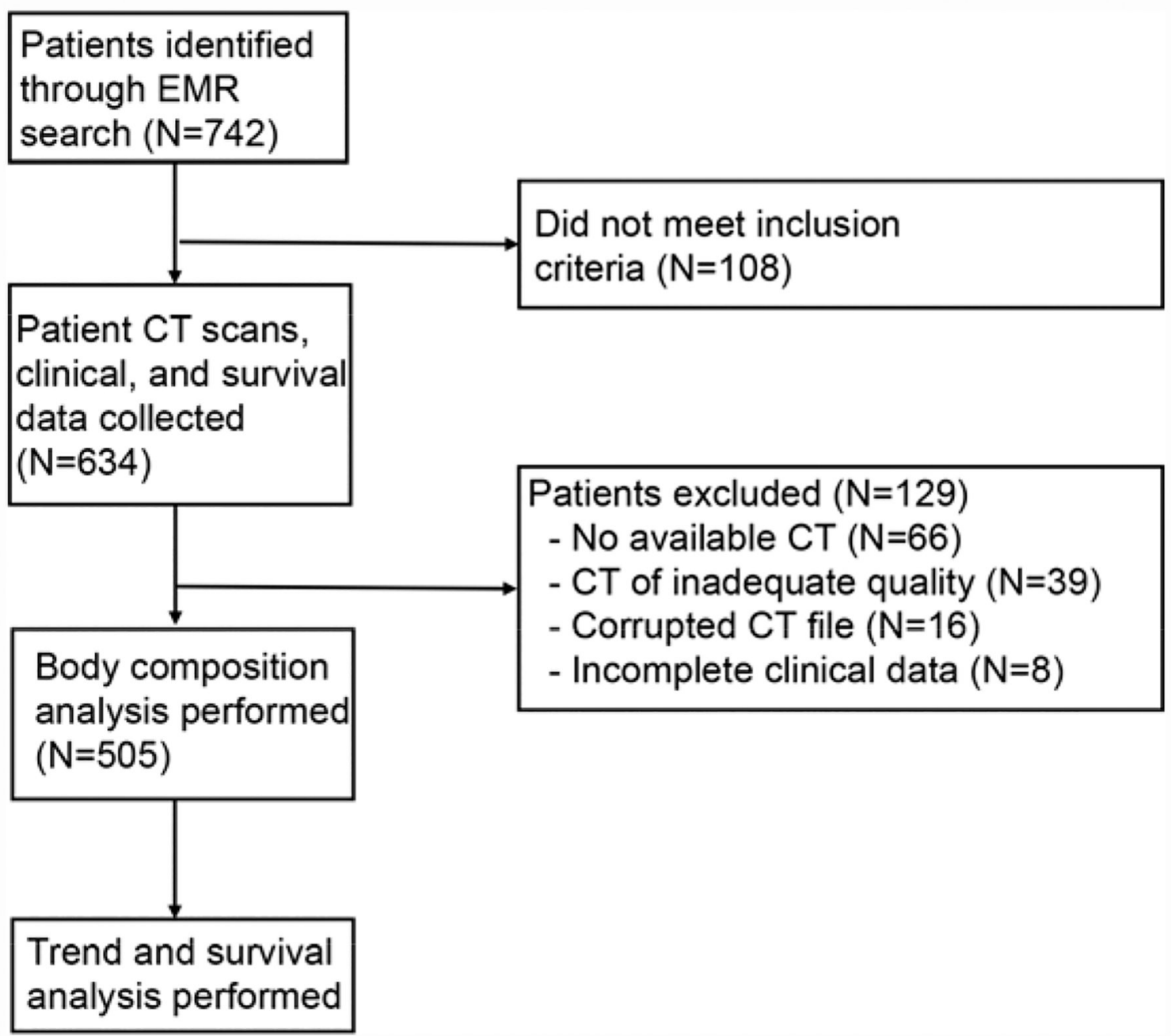

Figure 1: 
A.

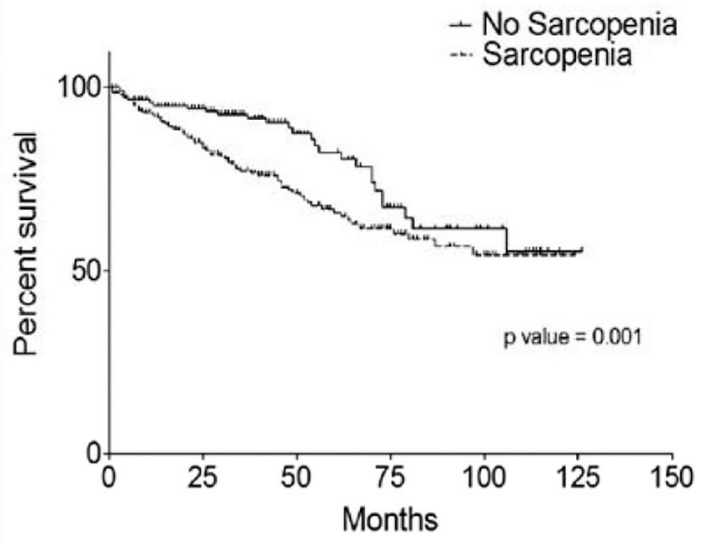

B.

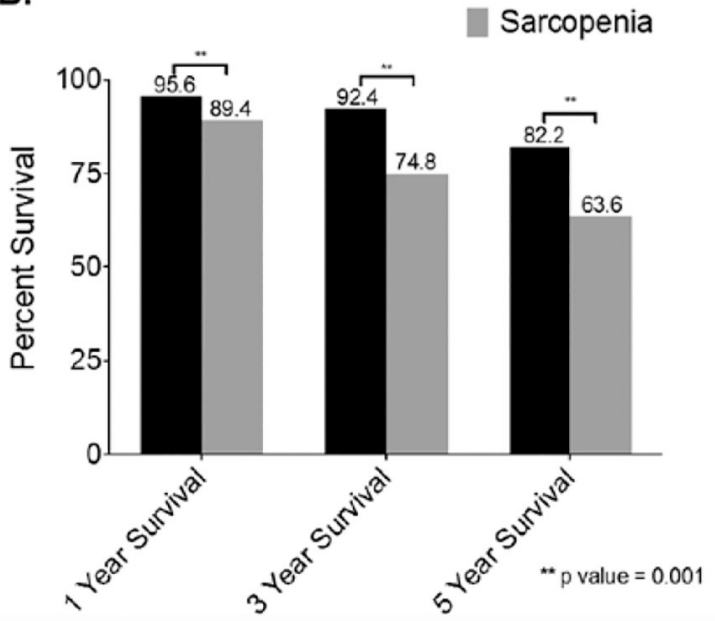

c.

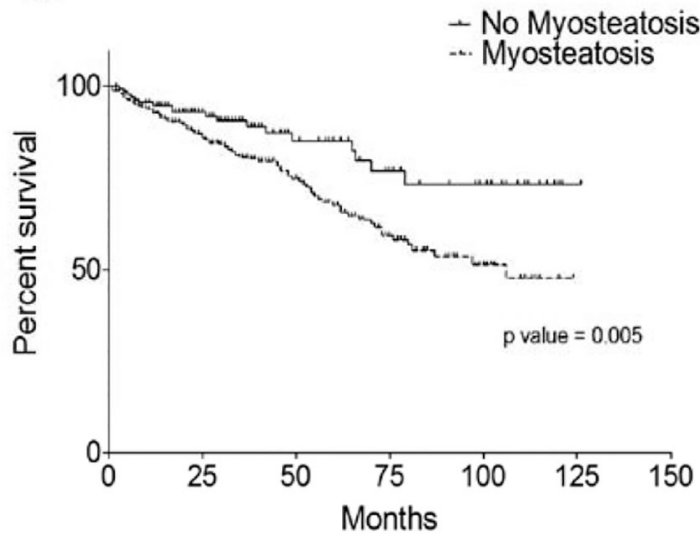

D.

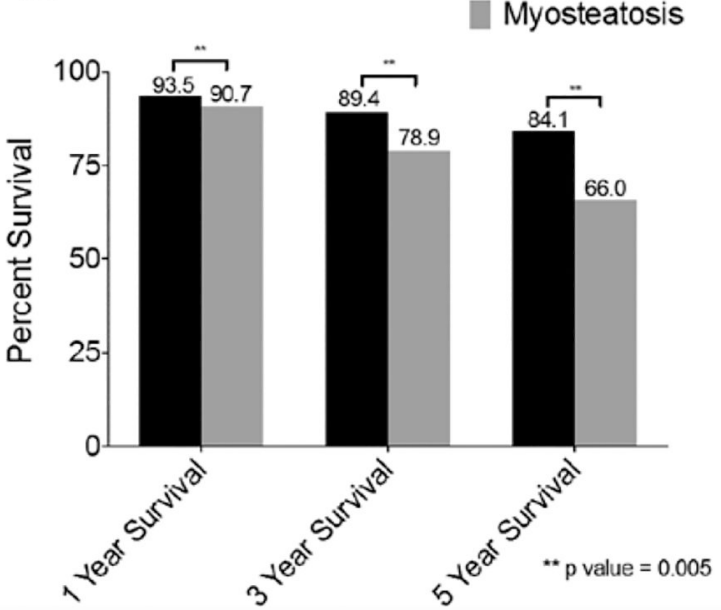

Figure 2: 
A)

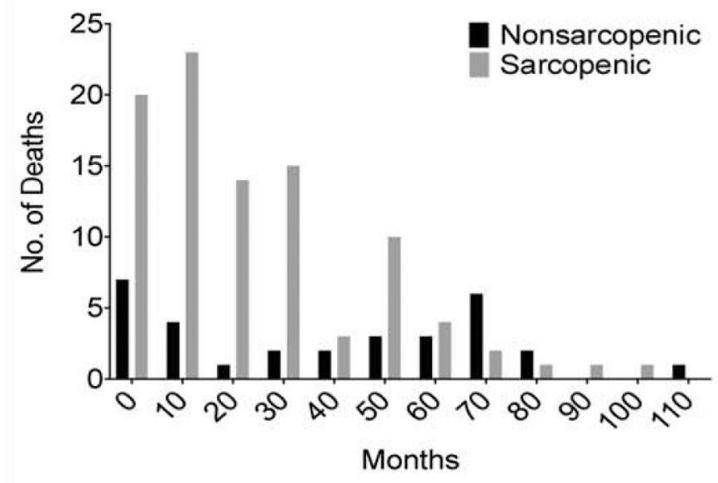

B)

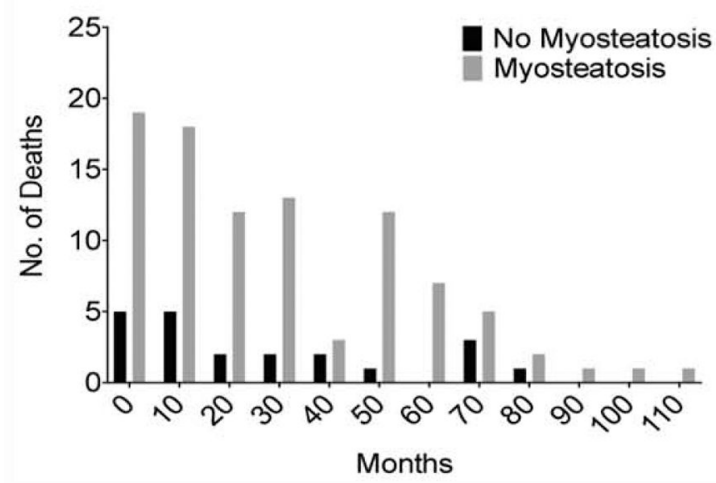

C)

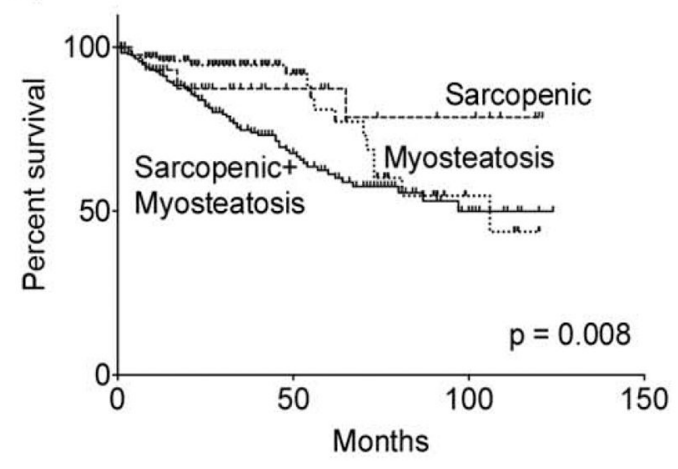

D)

\begin{tabular}{l|c|c|c|c} 
Variable (N) & $\begin{array}{c}\text { Median OS } \\
\text { (months) }\end{array}$ & $P$ & HR $(95 \%$ Cl) & $P$ \\
\hline $\begin{array}{l}\text { Sarcopenia + } \\
\text { Myosteatosis (247) }\end{array}$ & 97 & 0.008 & Reference & Reference \\
$\begin{array}{l}\text { Sarcopenia only (45) } \\
\text { Myosteatosis only }\end{array}$ & 106 & & $0.46(0.21-0.99)$ & 0.05 \\
(102) & & $0.51(0.30-0.86)$ & 0.012 \\
\hline
\end{tabular}

Figure 3: 


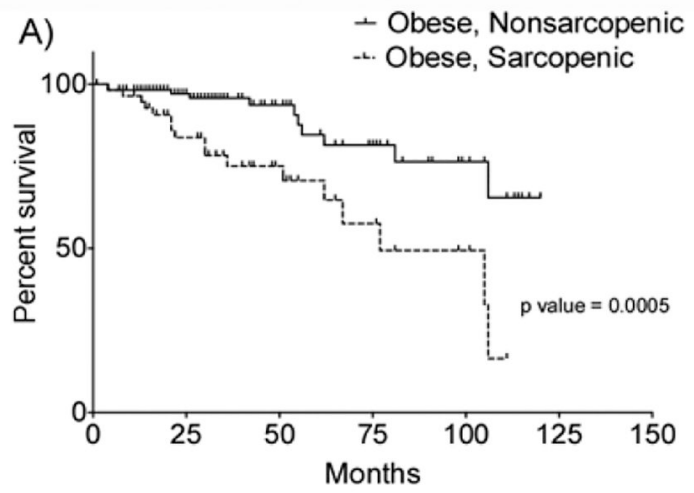

C)

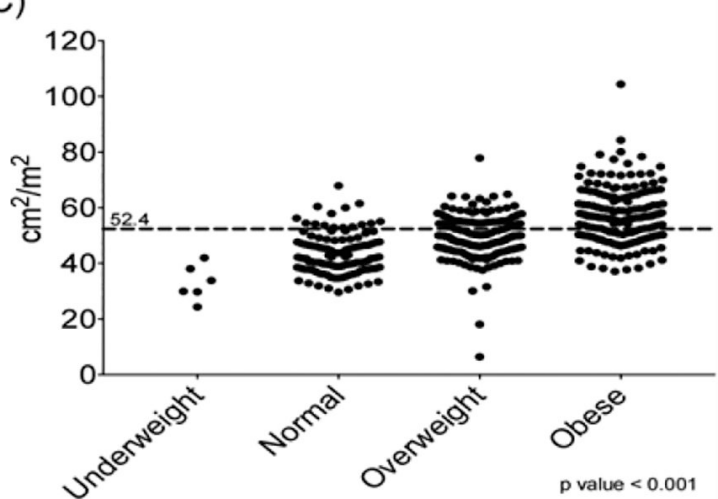

B)

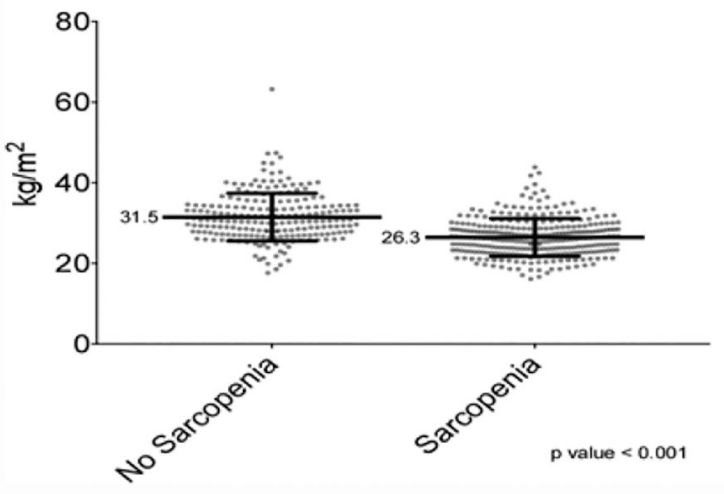

D)

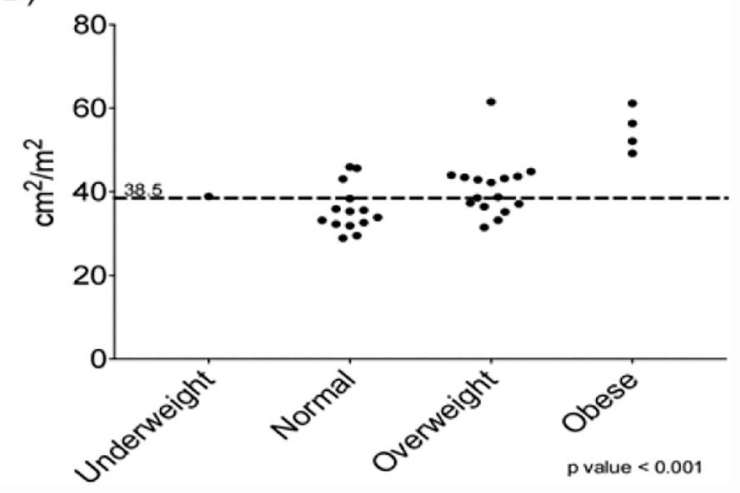

Figure 4: 


\section{을 \\ 골}



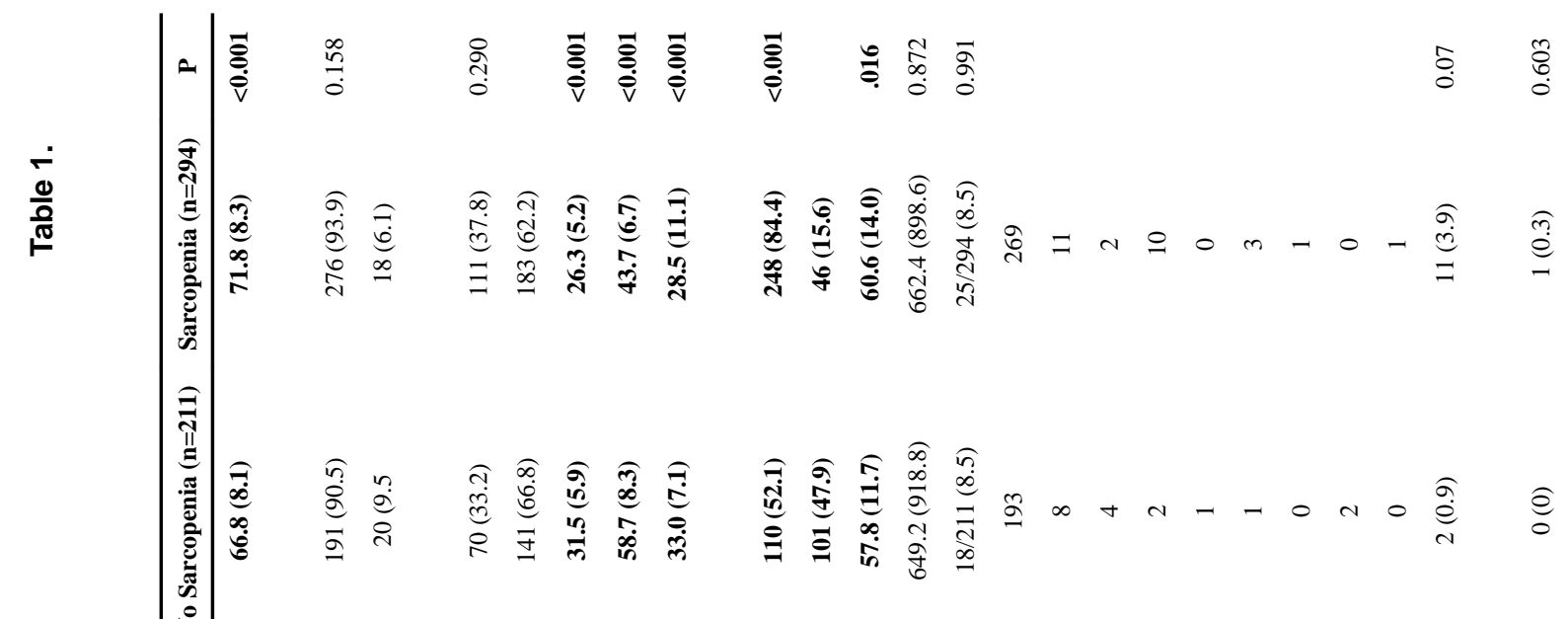

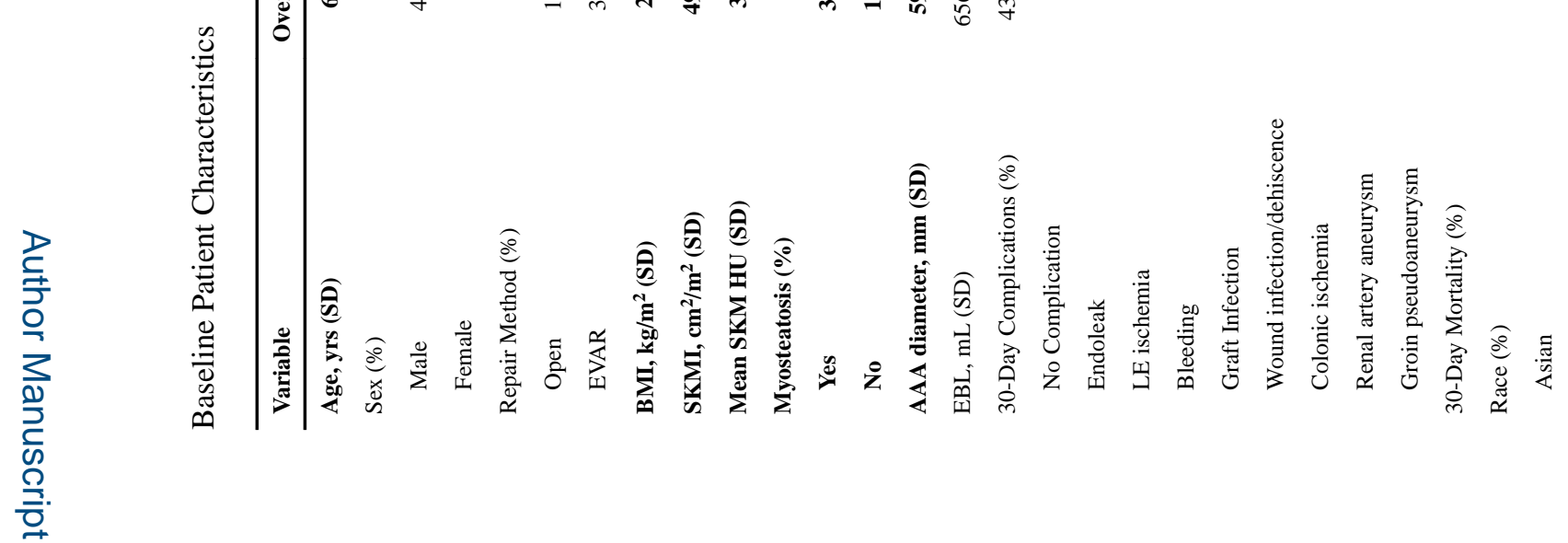

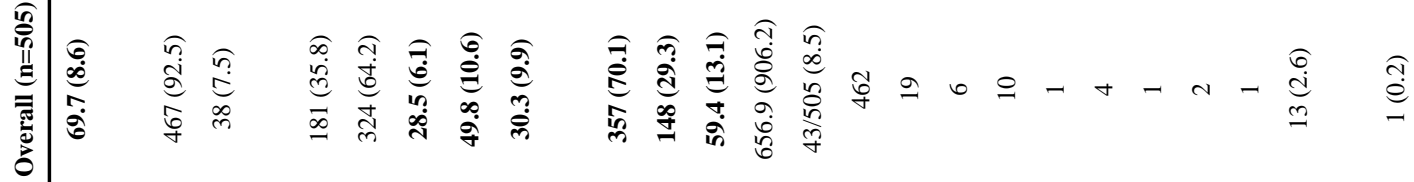

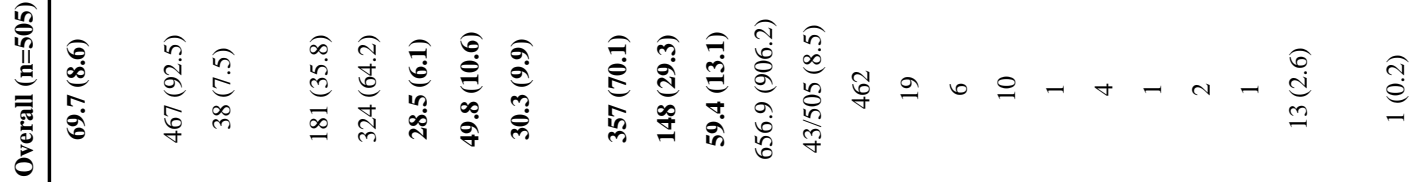

:

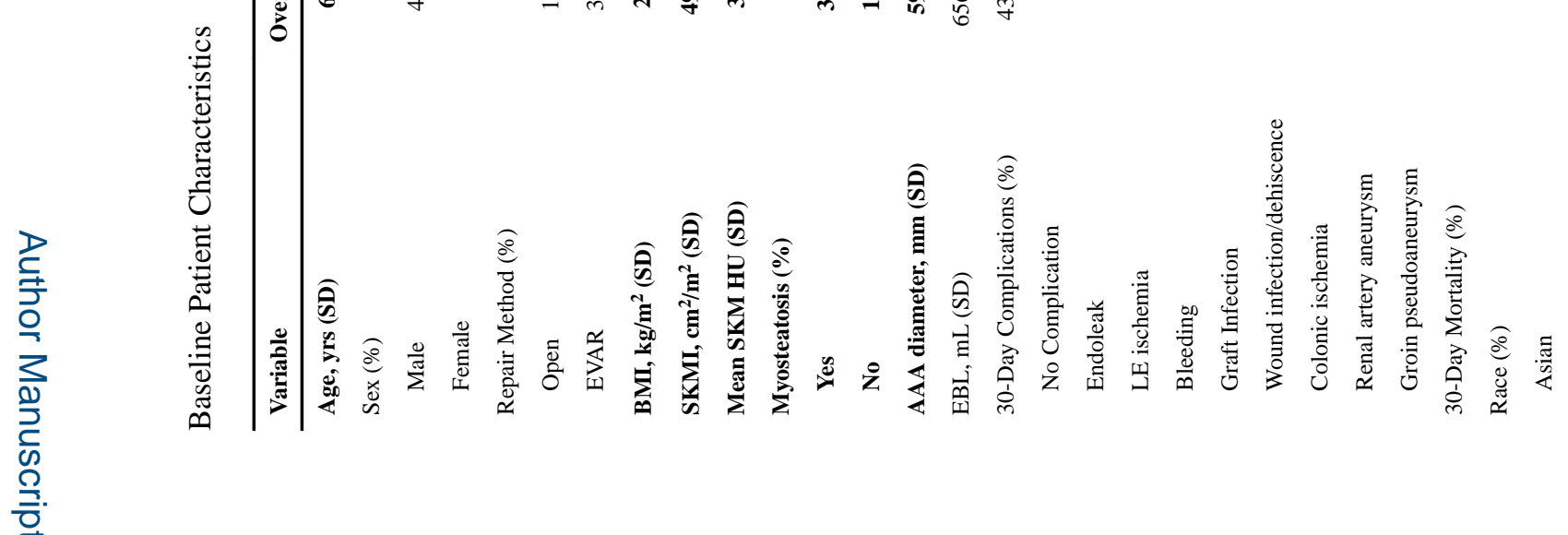

JCSM Clin Rep. Author manuscript; available in PMC 2019 April 10. 
Kays et al.

Page 16

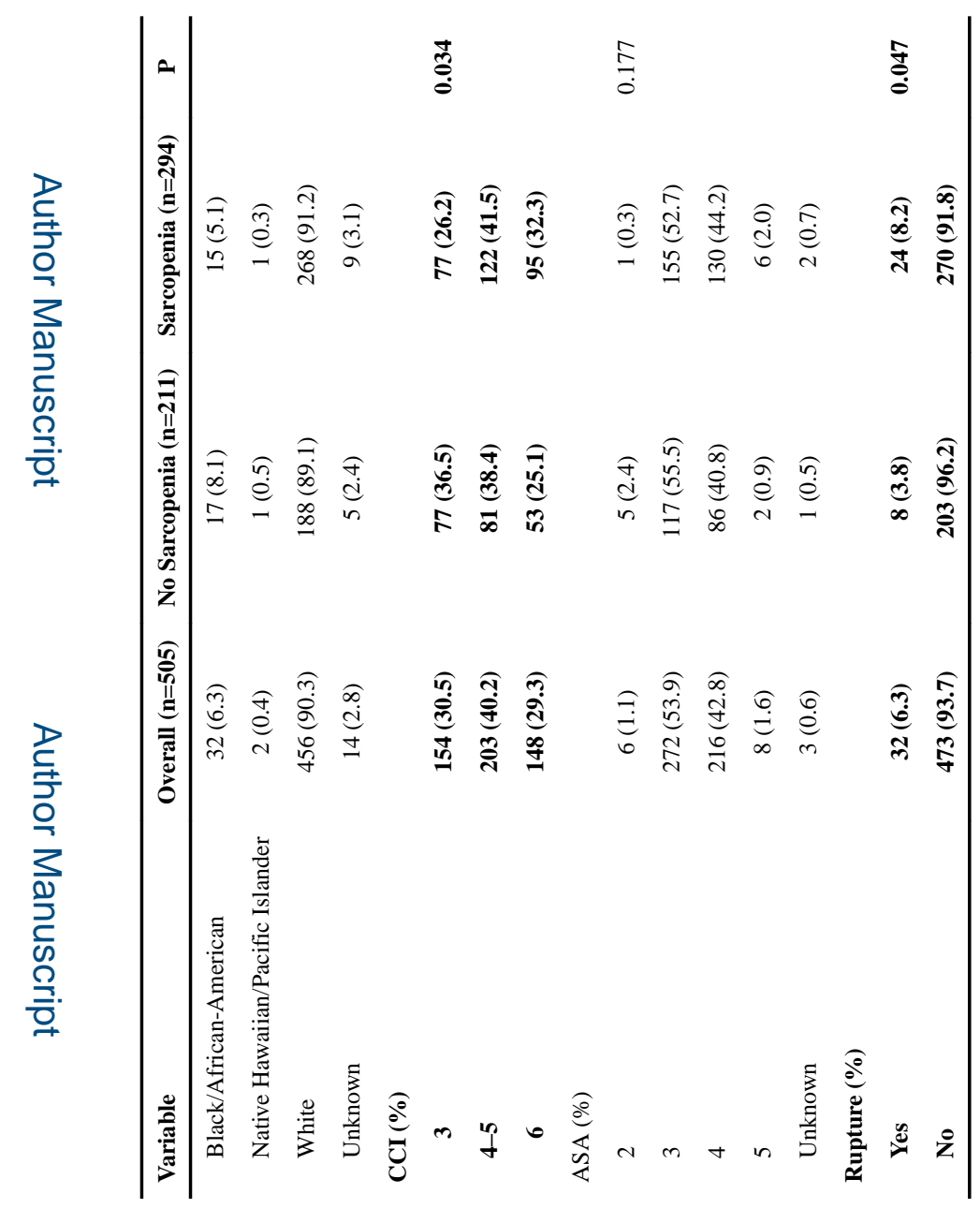

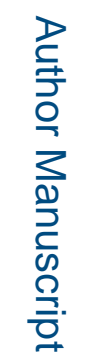

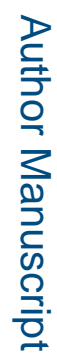

JCSM Clin Rep. Author manuscript; available in PMC 2019 April 10. 


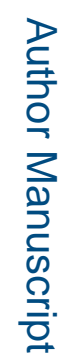

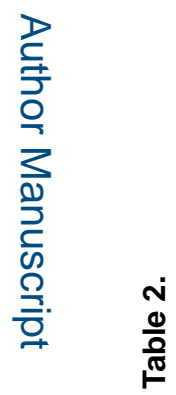

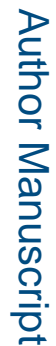

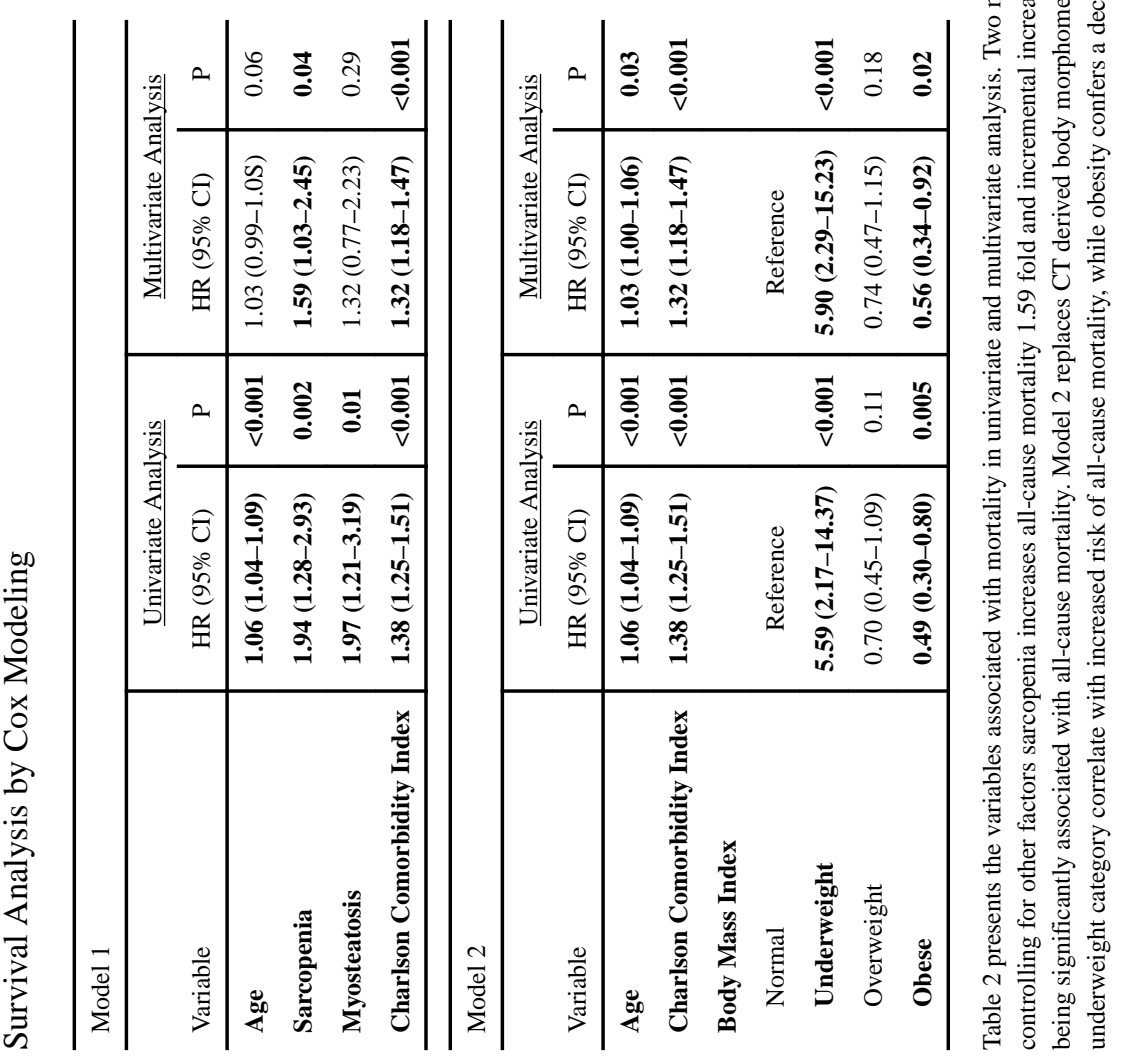

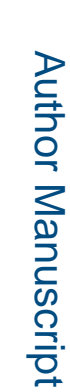

\section{중}

氖造

융 형

急

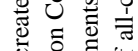

$\frac{0}{\circ}$

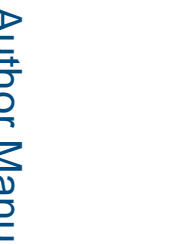

